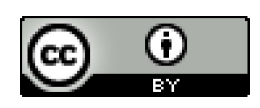

Esta obra está sob o direito de Licença Creative Commons Atribuição 4.0 Internacional.

\title{
HERMENÊUTICA: ATUAÇÃO NA HISTÓRIA DA EDUCAÇÃO BRASILEIRA
}

\author{
Ingrid Francinne Accioly Lira ${ }^{1}$
}

\section{RESUMO}

A hermenêutica, como também a educação encontra uma base comum de sustentação: a experiência. A singularidade como se realiza a experiência na vida concreta, ou na existência, gera atitudes que mostram uma forma de compreender as coisas, os fatos e a si mesmo. $\mathrm{O}$ objetivo deste trabalho foi discutir sobre a hermenêutica e sua atuação na história da educação brasileira. A estratégia metodológica definida para este estudo foi uma revisão de literatura tradicional, não sistemática, descritiva, de natureza qualitativa, com análise de conteúdo de livros e artigo científico adquiridos em bibliotecas físicas e virtuais. A análise sobre os aspectos básicos da dimensão da hermenêutica, buscando aproximá-la ao campo da educação retroalimentará a perspectiva de um pensamento crítico, fundamentado na compreensão hermenêutica do processo de ensino-aprendizagem, e por consequência proporcionará uma estreita e profunda relação entre os elementos desse processo. Conclui-se que a influência e contribuição relevante da hermenêutica para a educação brasileira estabelece uma aproximação reflexiva entre ela e a educação, no processo de desenvolvimento do homem enquanto ser no mundo e do mundo, e sua evolução na produção e aquisição do processo do conhecimento.

Palavras-chave: Hermenêutica. Educação. Aprendizagem. Conhecimento.

\footnotetext{
1 Doutoranda e mestre em Ciências da Educação, UDS. Especialista em Gerenciamento da Construção Civil. Engenheira Civil - CESMAC, 2006.
} 


\section{INTRODUÇÃO}

A Educação e a Hermenêutica têm uma relação profunda, sendo de suma importância para a transformação e aperfeiçoamento do ser, onde a educação deve ser refletida a luz da hermenêutica. Visando a possibilidade de compreender a experiência da pesquisa em educação a partir de suas próprias bases de justificação e legitimação, a hermenêutica consiste numa abordagem filosófica de postura interpretativa e compreensiva do

\section{METODOLOGIA}

A estratégia metodológica definida para este estudo foi uma revisão de literatura tradicional, não sistemática,

\section{RESULTADOS E DISCUSSÕES}

Após análise do material pesquisado foi possível desenvolver três categorías temáticas: o que é hermenêutica?, educação e conhecimento a partir da fenomenologia hermenêutica e contribuição da hermenêutica para educação.

\section{O que é hermenêutica?}

Hermenêutica é um ramo da filosofia que estuda a teoria da interpretação, que pode referir-se tanto à arte da interpretação, ou a teoria e treino de interpretação. texto/tradição em seu próprio horizonte de sentido.

A análise sobre os aspectos básicos da dimensão da hermenêutica buca aproximá-la ao campo da educação retroalimentará a perspectiva de um pensamento crítico, fundamentado na compreensão hermenêutica do processo de ensino-aprendizagem.

Diante do contexto mencionado anteriormente, este trabalho tem por objetivo discutir sobre a hermenêutica e sua atuação na história da educação brasileira. descritiva, de natureza qualitativa, com análise de conteúdo de livros e artigo científico adquiridos em bibliotecas físicas e virtuais.

Segundo a filosofia, a hermenêutica aborda duas vertentes: a epistemológica, com a interpretação de textos e a ontológica, que remete para a interpretação de uma realidade.

Para Strong é uma suposta derivação de Hêrmes, o deus da mitologia grega cuja função seria a de "o mensageiro das divindades gregas”. Em Atos 14:12 o povo de Listra chamou a Barnabé Jupiter (Lit. Zeus, o deus supremo do panteão grego) e a Paulo, Mercúrio (lit. de Hermes, filho de Zeus e o principal mensageiro), "pois era este o principal portador da palavra". 
Osborne definiu a tarefa interpretativa sob três perspectivas essenciais:

"Primeira, a hermenêutica é uma ciência, uma vez que faz uma classificação lógica e ordenada das leis da interpretação [...] Segunda, é a de que a hermenêutica é uma arte, uma vez que é um conhecimento que se adquire e exige tanto imaginação quanto competência para aplicar as "leis" às passagens selecionadas ou aos livros. É uma arte que não pode ser simplesmente aprendida numa sala de aula, mas é consequência de uma prática constante em sua área de atuação [...] Terceira e mais importante, é a de que a hermenêutica, quando utilizada para interpretação das Escrituras, é um ato de caráter espiritual realizado na dependência do Espírito Santo." (OSBORNE, Grant R., 2009, p. 26)

Os autores mencionados acima apontam que a hermenêutica se caracteriza pela interpretação ou compreensão dos textos seja de teor religioso ou filosófico, bem como dos sentidos e/ou significação das palavras que se encontram nos mesmos.

Diante do exposto é de suma importância explanar as vertentes hermenêuticas. Uma, compreende a origem, a estrutura, os métodos e a validade do conhecimento, e também é conhecida como teoria do conhecimento e relaciona-se com a metafísica, a lógica e a filosofia da ciência. A outra, por sua vez retratava a natureza do ser, a existência e a realidade, procurando definir as categorias fundamentais e as relações do "ser enquanto ser”. Abrange também alguns conteúdos abstratos como a existência de determinadas entidades, $\mathrm{O}$ que pode dizer que existe, qual seu significado do ser, vertente que foi aprimorada e difundida por Heidegger e Gadamer.

A analítica heideggeriana, ainda que existencial ao seu próprio modo, mantém fundamentalmente uma intenção transcendental, que deve ser levada em consideração quando da sua apropriação para o desenvolvimento de uma hermenêutica de base histórica. Enquanto Gadamer acredita que no contexto da analítica existencial ainda não haveria um desenvolvimento adequado do modo de ser da vida, o que seria uma tarefa a ser realizada. Ainda assim, não seria adequado compreender o aspecto existencial de tal analítica como algo que carrega uma intenção de determinar um ideal para a existência.

É notório em relação ao método filosófico que Heidegger é mais 'analítico', aristotélico, de modo que Gadamer pauta-se pelo dialógico, dialético, socráticoplatônico. Embora o projeto filosófico gadameriano não seja compreensível nem factível sem a contribuição de Heidegger, ele possui especificidades e uma originalidade que precisa ser levada em conta quando nos adentramos no terreno da hermenêutica.

É comum nos dois autores [Gadamer e Heidegger] é a ideia de que a sentença não pode ser tomada como uma 
entidade semântica autossuficiente. (...) O atual sentido da reivindicação de universalidade da hermenêutica repousa na sua estrutura motivacional da linguagem, no verbum interius, o qual deve ser entendido como o actus exercitus no seu sentido completo, de acordo com (GRONDIN, 1995, p. 94-5). Grondin procura apontar para a influência linguística de Heidegger sobre Gadamer.

A importância desta pesquisa se dá tendo em vista a relação estabelecida entre a teoria interpretativa e a filosofia da história, resultando na ciência social interpretativa, possibilitando $\mathrm{o}$ desenvolvimento da interpretação, da análise das ciências e do ser.

Contudo, a hermenêutica como teoria universal da compreensão e interpretação, proporciona a reconstrução a partir da finalidade e circunstâncias oriundas do autor a sua ideia.

\section{Educação e conhecimento a partir da fenomenologia hermenêutica}

Para o processo de educação, uma das questões centrais está vinculada a forma como se estrutura ou se configura uma determinada compreensão. Compreender que a de educação e seus referenciais se desenvolvem de diferentes modos na compreensão passa pela aplicação do movimento dialógico para o próprio pensamento, ou seja, em um diálogo que se dá consigo mesmo.

A vinculação existencial da compreensão como também o caráter efeitual da história, evidenciados pela hermenêutica como fato da realidade linguística do ser humano, interfere diretamente $\mathrm{o}$ entendimento sobre a educação.

Contudo, a educação se adentra na existência como acontecimentos de encontro com a realidade, com os outros e consigo mesmo no meio definido como linguagem, tendo o campo da tradição como limite.

A fenomenologia hermenêutica recomenda olhar o mundo não como fato, nem como mundo em si, nem como aquilo que é pensado, mas sim como uma realidade pré-reflexiva.

A tradição da fenomenologia e da hermenêutica não almejaram criar uma filosofia da educação. Gadamer (1999) fundamenta sua hermenêutica filosófica, apoiando-se na tradição humanista histórica alemã, retoma o conceito de Bildung (Formação), não como uma capacidade, nem como posse de conhecimento, mas como apropriação do humano, desenvolvimento pessoal para o auto encontro e a melhor maneira de viver intersubjetivamente. Portanto, a educação se refere a uma concepção holística. 
O pensamento gadameriano de Bildung determina o elemento aglutinador das ciências, enquanto a termo que alude à totalidade que define o modo como uma época histórica vincula a sua compreensão de mundo. Como também, se refere a um ideal educativo ou educação com sentidos culturais, históricos, crítico e liberal.

De certo modo, a hermenêutica, como também a educação encontra uma base comum de sustentação: a experiência. A singularidade como se realiza a experiência na vida concreta, ou na existência, gera atitudes que mostram uma forma de compreender as coisas, os fatos e a si mesmo.

O acontecimento hermenêutico corresponde à finitude humana, mas a essa finitude corresponde, por sua vez, uma infinidade de sentido [...]." (HERMANN, 2002, p. 72).

Portanto, fica livre a esta infinidade de sentidos possíveis de serem elaborados pela experiência condiciona o ser em um processo de educação ao longo da vida. Através da compreensão, o mundo se demonstra (mostra) como linguagem, trazendo nos preconceitos a base histórica da vida concreta e que permite a elaboração projetiva de um sentido.

De acordo com Stein (1996, p. 30), o sentido da estrutura é quando perguntamos por algo sobre o mundo e não por algo no mundo. Entretanto, assim como a compreensão, o educar-se faz a exigência de mobilidade do sentido, pois a compreensão se estabelece dentro de uma circularidade, isto é, não adianta apenas falar que a razão ou a consciência elaboram compreensão, porém é possível notar que a própria história e a tradição participam desta produção. "A experiência educativa, enquanto hermenêutica, exige a exposição ao risco, às situações abertas e inesperadas, coincidindo com a impossibilidade de assegurar a tais práticas educativas uma estrutura estável, que garanta o êxito da ação interventiva." (HERMANN, 2003, p. 86).

\section{Contribuição da hermenêutica para educação}

A hermenêutica ficou conhecida como uma ferramenta adequada às ciências humanas, ou seja, em oposição ao processo analítico, o qual informa e analisa o objeto, seria um processo interpretativo, compreensivo, adequado à interpretação das coisas humanas, a qual permite qualificar a educação como uma experiência feita pelo próprio sujeito, de mobilização dos próprios preconceitos e do projeto exposto como um entendimento acabado.

A educação considerada como fenômeno humano independe da escola, mas compreende toda a realidade social e de relações entre as pessoas, visto que o 